\title{
Endoscopic Reintervention for Recurrence of Malignant Biliary Obstruction: Developing the Best Strategy
}

\author{
Mamoru Takenaka and Masatoshi Kudo \\ Department of Gastroenterology and Hepatology, Kindai University Faculty of Medicine, Osakasayama, Japan
}

Article Info
Received May 21, 2021
Revised July 22, 2021
Accepted August 24, 2021
Published online February 23, 2022
Corresponding Author
Mamoru Takenaka
ORCID https://orcid.org/0000-0001-7308-4311
E-mail mamoxy045@gmail.com

Drainage therapy for malignant biliary obstruction (MBO) includes trans-papillary endoscopic retrograde biliary drainage (ERBD), percutaneous transhepatic biliary drainage (PTBD), and transgastrointestinal endoscopic ultrasound-guided biliary drainage (EUS-BD). With the development of chemotherapy, many MBO cases end up needing endoscopic reintervention (E-RI) for recurrent biliary obstruction. To achieve a successful E-RI, it is necessary to understand the various findings regarding $\mathrm{E}-\mathrm{RI}$ in $\mathrm{MBO}$ cases reported to date. Therefore, in this review, we focus on E-RI for ERBD of distal MBO, ERBD of hilar MBO, and EUS-BD. To plan an appropriate E-RI strategy for biliary stent occlusion for $\mathrm{MBO}$, the following must be considered on a case-by-case basis: the urgency of the drainage, the cause of the occlusion, the original route of drainage (PTBD/ERBD/EUS-BD), the initial stent used (plastic stent or self-expandable metallic stent), and in the case of self-expandable metallic stents, the type used (fully covered or uncovered). Regardless of the original method of stent placement, if the inflammation caused by obstructive cholangitis is severe and/or the patient is in shock, PTBD should be considered as the first choice. Finally, it is important to keep in mind that in many cases, performing E-RI will be difficult. (Gut Liver 2022;16:525-534)

Key Words: Jaundice, obstructive; Stent; Interventional ultrasonography

\section{INTRODUCTION}

Drainage therapy for malignant biliary obstruction (MBO) is a clinically important procedure for the treatment of pancreatobiliary disease. The most common drainage routes include trans-papillary endoscopic retrograde biliary drainage (ERBD), percutaneous transhepatic biliary drainage (PTBD), and trans-gastrointestinal endoscopic ultrasound-guided biliary drainage (EUS-BD). Each procedure comes with inherent strengths and weaknesses.

For example, ERBD, whether be placed above or across the papilla, is inserted trans-papillary by endoscopic retrograde cholangiopancreatography (ERCP), thus presenting a risk of postoperative pancreatitis. ${ }^{1}$ EUS-BD and PTBD also have the same risk of postoperative pancreatitis when creating internal trans-papillary drainage, but if drainage is performed only on the peripheral side of the stenosis, the risk of pancreatitis and the risk of stent occlusion by tumor are both reduced. However, PTBD has cosmetic problems with drainage tubes and EUS-BD is not mature enough to be performed in any hospital. The best drainage procedure to use for $\mathrm{MBO}$ cases is determined by the policy of each institution as well as the intention of the endoscopist.

The factors which influence the outcome of drainage therapy in $\mathrm{MBO}$ patients can be broadly divided into patient-related factors and stent-related factors (Table 1). ${ }^{2}$

Patient-related factors include the disease causing MBO, the anatomy of each case, and advances in chemotherapy. Stent-related factors include whether the stent used was a self-expandable metallic stent (SEMS) or plastic stent (PS), whether a SEMS was uncovered, partially covered, or fully covered, whether the drainage area was unilateral or bilateral, whether or not the lower end of the stent exceeded the papilla, and in hilar MBO, whether the method of multiple stenting used was stent-in-stent (SIS) or side-by-side (SBS) placement.

These factors are considered on a case-by-case basis to establish an optimal drainage strategy for the longest 
Table 1. Factors That Can Influence the Outcome of Drainage Therapy for MBO

Patient-related factors

- Disease causing MBO

- Anatomy of each case

- Advances in chemotherapy

Stent-related factors

- SEMS or PS

- Uncovered or partially covered or fully covered (SEMS)

- Unilateral od bilateral (drainage area)

- Across the papilla or above the papilla (the lower end of the stent)

- SIS or SBS (in hilar MBO)

MBO, malignant biliary obstruction; SEMS, self-expandable metallic stent; PS, plastic stent; SIS, stent-in-stent; SBS, side-by-side.

possible drainage period. However, recent advances in chemotherapy have greatly improved the prognosis of $\mathrm{MBO}$ cases. Even if the cause of $\mathrm{MBO}$ is pancreatic cancer or cholangiocarcinoma, the prognosis is more than one year, and if the cause of $\mathrm{MBO}$ is lymph node metastasis of colorectal cancer or liver cancer, there is a possibility of long-term prognosis.

This means that many $\mathrm{MBO}$ cases will encounter the need for endoscopic reintervention (E-RI) for recurrent biliary obstruction (RBO). Therefore, ideal drainage for $\mathrm{MBO}$ is drainage performed while keeping potential future E-RIs in mind from the time of initial drainage.

The factors which influence the outcome of drainage therapy in $\mathrm{MBO}$ patients mentioned above are equally important in E-RI and it is necessary to understand the various findings regarding E-RI in $\mathrm{MBO}$ cases reported in the literature. In this review, we focus on E-RI for ERBD of distal MBO (D-MBO), ERBD of hilar MBO, and EUS-BD.

\section{E-RI OF ERBD FOR D-MBO}

The most widely used drainage method for D-MBO is ERBD, however, PTBD has been performed in cases where the scope cannot reach the papilla due to duodenal stenosis caused by cancer. In recent years, EUS-BD has emerged as another option, and many comparative studies of ERBD and PTBD for D-MBO have been reported.

A meta-analysis comparing 112 EUS-BD cases and 110 $\mathrm{ERBD}$ as an initial drainage treatment for D-MBO, reported that there was no significant difference in technical success rate $(91.96 \%$ vs $91.81 \%, \mathrm{p}=0.97)$, clinical success rate ( $84.81 \%$ vs $85.53 \%, \mathrm{p}=0.90)$, or complication rate $(12.5 \%$ vs $22.7 \%, \mathrm{p}=0.54$ ) between the procedures. The stent dysfunction rate was significantly lower in the EUS-BD group $(\mathrm{p}=0.001),{ }^{3}$ however EUS-BD is not yet a procedure that can be performed at any facility. So, in D-MBO cases, most of the stent occlusion cases that are problematic in daily practice are ERBD occlusions.

The strategy for the reintervention of ERBD in D-MBO changes depending on whether the initially placed stent was a PS or SEMS. If the first stent is a PS, a planned or ondemand E-RI is relatively easy to perform. On the other hand, if a SEMS is used, the type of SEMS used (covered or uncovered) greatly influences the strategy used for the reintervention.

There have been many studies on whether covered or uncovered SEMSs are recommended as initial drainage for $\mathrm{D}-\mathrm{MBO}$. However, they have different conclusions regarding whether covered or uncovered SEMSs are better for D$\mathrm{MBO}^{4-8}$

\section{E-RI for uncovered SEMS in D-MBO}

If the stent was an uncovered SEMS, the cause of RBO was presumed to be tumor ingrowth through the stent mesh or tissue hyperplasia through the stent mesh. So, in E-RI to uncovered SEMS, placement of the second PS or SEMS within an obstructed uncovered SEMS is recommended (in a SIS fashion) because the removal of an uncovered SEMS is difficult. ${ }^{9-11}$

Regarding the second stent used for E-RI of D-MBO, a previous comparative study assessing which stent is best (covered SEMS vs uncovered SEMS vs PS) was conducted in South Korea. ${ }^{12}$ As a result, they found that covered SEMSs had significantly longer patency than PSs as the second stent. What made this analysis so clinical is that it performed a sub-analysis on the combination of the first and second SEMS (covered+covered, covered+uncovered, or uncovered+covered). The authors concluded that double biliary SEMS placement using at least one covered SEMS (in the primary and/or secondary procedure) provided longer cumulative stent patency and survival than using uncovered SEMSs in both procedures. A similar trend was reported in other reports. ${ }^{13-15}$ For example, a systematic review conducted in the United States showed that there was no difference in both the re-occlusion rate and stent patency between a SEMS and PS inserted as a second stent, but this analysis was a retrospective analysis. ${ }^{16}$

\section{E-RI for fully covered SEMS in D-MBO}

On the other hand, if the stent is a fully covered SEMS, stent removal is possible. As with PS replacement, the SEMS can be removed, and a new SEMS can be inserted (Fig. 1).

It has been reported that an obstructed fully covered SEMS is best managed by stent removal and placement of a new fully covered SEMS rather than attempts at clearance by balloon sweeping. In this report, the success rate of the 

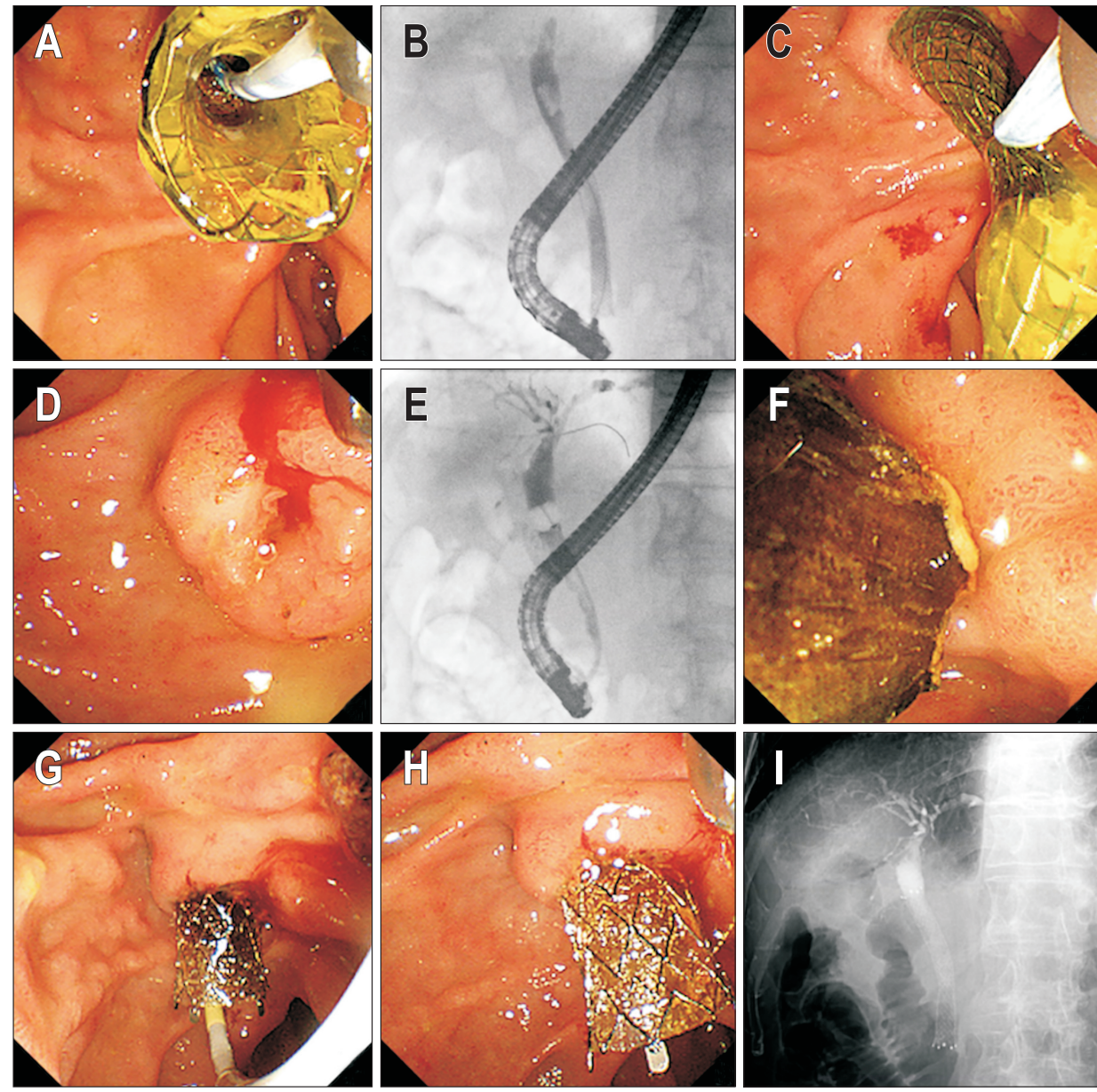

Fig. 1. Endoscopic reintervention of a fully covered self-expandable metallic stent (SEMS) for distal malignant biliary obstruction. (A) Biliary cannulation through the opening of a fully covered SEMS is easy to perform. (B) In this case, the patient had obstructive cholangitis due to stent obstruction and common bile duct stones. Endoscopic retrograde cholangiography confirmed a defect due to stones. (C) A fully covered SEMS was grasped by the snare and removed without resistance. (D) Biliary cannulation after SEMS removal is relatively easy. (E) Removal of the stone was performed using a balloon catheter. (F) Stone removal was successful. (G) An attempt was then made to insert a new fully covered SEMS. The device easily passed through the stenosis. (H) New fully covered SEMS placement was successful. (I) The new fully covered SEMS was visible through fluoroscopy.

initial SEMS removal using a polypectomy snare or forceps was $94.6 \%$ (35/37). The reasons for unsuccessful removal included the SEMS migrating into the common bile duct (CBD) and ingrowth into the mesh due to membrane breakdown. ${ }^{17}$

\section{E-RI for partially covered SEMS in D-MBO}

The partially covered SEMS was designed to prevent migration, which is the weakest point of the fully covered SEMS, by providing membrane-less mesh parts at both ends of the stent. ${ }^{18}$ A prospective multicenter comparative study of fully covered SEMS and partially covered SEMS for D-MBO reported that no significant differences were found in the rate of $\mathrm{RBO}$ or the time to $\mathrm{RBO}$. A notable result of this study was that the rate of stent migration also did not differ significantly between the two groups. Based on the fact that removal of the fully covered SEMSs was successful in all attempted cases in this study, it is recommended that a fully covered SEMS be selected for the initial drainage of D-MBO with the possibility of E-RI. ${ }^{19}$

If the initial SEMS in the E-RI is partially covered by SEMS, it is desirable to identify a fully covered SEMS with a length that can cover the membrane-less mesh parts to prevent ingrowth and tissue hyperplasia formation in the mesh part of the initial partially covered SEMS. However, in this case, a fully covered SEMS that is longer than the initial partially covered SEMS is required, but since there is a risk that the upper end of the longer fully covered SEMS will encounter the hepatic hilum, a SIS with PS is recommended. 


\section{E-RI OF ERBD FOR MHBO}

In E-RI for malignant hilar biliary obstruction (MHBO), it is important to first identify areas where drainage treatment should be prioritized. Importantly, developing drainage strategies for $\mathrm{MHBO}$ is more complex and thoughtful in terms of anatomy than $\mathrm{D}-\mathrm{MBO}$.

If the area requiring drainage treatment is different from the area where the ERBD was originally indwelled, new drainage treatment would be required in that area. In advanced MHBO cases (like Bismuth classification type IV), ${ }^{20,21}$ many areas require drainage rather than just one. In such cases, multiple ERBD stentings or a combination treatment of ERBD, PTBD, and EUS-BD is needed. ${ }^{22}$ In this situation, it is desirable to determine the priority of the area where the drainage treatment is prioritized using a pretreatment image evaluation. It has been reported that the volume of the liver needing treatment with drainage has a significant effect on the effective period of drainage treatment. ${ }^{23,24}$ Prior to performing an E-RI, it is very important to confirm the liver volume by computed tomography and assess bile duct anatomy using magnetic resonance cholangiopancreatography in order to determine which areas should be prioritized for drainage.

On the other hand, if the area requiring drainage treatment is the same area where the ERBD was originally indwelled, the first placed stent occlusion is likely the cause of the RBO. In this situation, the success of the E-RI for MHBO is greatly influenced by whether the SEMS or PS is indwelled.

\section{E-RI for PS in MHBO}

If the first stent are PSs, the E-RI will succeed with a simple PS exchange.

In PS exchange, an inside PS may also be a useful option for E-RI for MHBO. An "above the papilla" SBS placement using an inside PS is expected to reduce the risk of retro- grade cholangitis, food impaction, and sludge formation because of the preservation of papillary function. In fact, a previous study reported that the stent patency of inside PS indwelled for E-RI was longer than that of the first inserted metallic stent (MS). ${ }^{25}$ In the future, it will be important to further improve inside PSs and analyze their effectiveness in many cases.

\section{E-RI for SIS placement SEMS in MHBO}

If a SEMS is initially inserted, whether the stent placement method used was SIS or SBS placement affected the strategy of the E-RI.

As some studies on E-RI after SIS have reported, ${ }^{11-13}$ an important consideration of E-RI for SIS placement is that SEMSs cannot be removed because they are uncovered SEMS. There is no other way but to insert a new PS or SEMS into each MS in an SIS fashion. If uncovered MSs are selected as newly inserted stents instead of PS, they cannot be removed, which makes the next E-RI even more difficult; therefore, PS or fully covered SEMS is recommended.

The most difficult aspect of E-RI for SIS placement is the manipulation of the guide wire through the uncovered SEMS mesh. In SIS placement, its success depends on the second stenting. ${ }^{26-28}$ Some metallic stents employed in SIS are designed to allow easier second stenting. ${ }^{29-32}$ However, the degree of stenosis during E-RI is worse than that during the initial ERBD because ingrowth due to progression of the primary disease from the mesh is the main cause of RBO. In particular, the difficulty in accessing the bile duct after insertion of the first stent during the initial ERBD is further exacerbated because the guidewire must pass through the mesh twice. Even if the guide wire breaks through the mesh twice, in many cases, the double mesh will prevent insertion of the stent (Fig. 2). Therefore, when using SEMS for E-RI with an SIS approach, an SEMS designed with a smaller gap between the delivery tip and
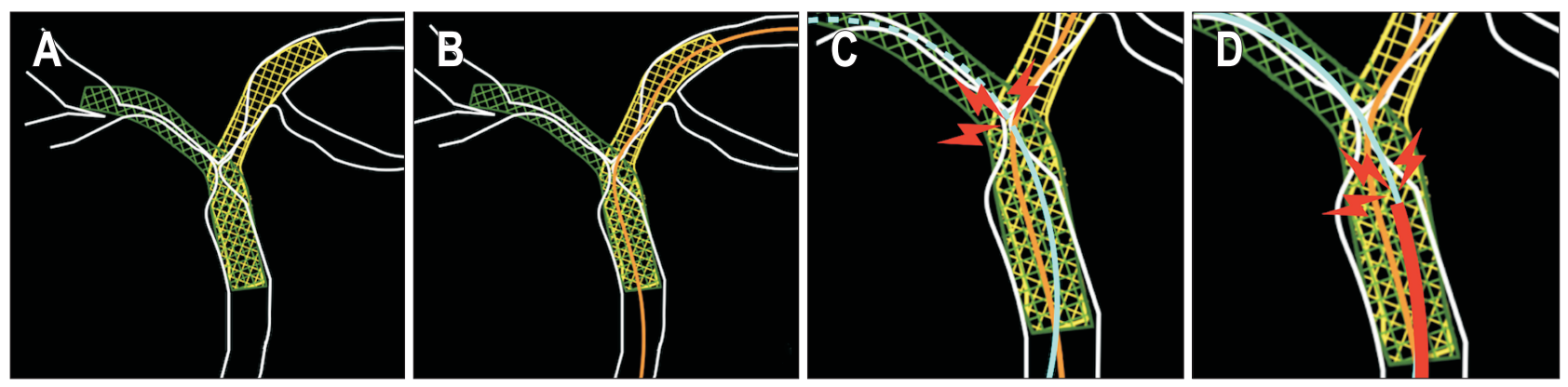

Fig. 2. Schema showing the difficulty of endoscopic reintervention using stent-in-stent (SIS) placement in hilar malignant biliary obstruction. (A) For SIS placement, the existing mesh overlaps the stenosis. (B) The guide wire can pass through the mesh of the second metallic stent (MS) detained during SIS detention. (C) However, it is necessary to pass the existing mesh in the stenosis twice to the bile duct where the first MS is placed, and it is difficult for the guide wire to pass through. (D) In addition, even if the guide wire passes, it is difficult for the device to pass. 
guide wire should be selected. ${ }^{33}$

\section{E-RI for SBS placement SEMS in MHBO}

In contrast, E-RI for SBS placement seems to be easier than SIS placement in terms of appropriate guidewire manipulation in the drainage area.

Unlike SIS placement, the lumens of the stents during SBS placement are independent, making it less difficult to pass through the SEMS mesh. However, during E-RI for SBS placement, guide wires must be inserted through the uncovered SEMS lower end opening in the CBD, which is sometimes difficult because it is performed under fluoroscopy. If the guide wire is inserted into the MS lumen through the mesh instead of the opening, even if the guide wire can be inserted beyond the stenosis into the drainage area, the new stent cannot pass through the stent mesh, resulting in E-RI failure. Furthermore, it is difficult to determine whether the guidewire was inserted from the mesh or from the stent opening in fluoroscopic images.

Importantly, a previous multicenter study assessing E-RI after SBS placement for MHBO demonstrated that E-RI after SBS placement is technically feasible and safe, but found that the success rate was significantly lower in patients with narrow CBDs and metastatic diseases. ${ }^{34}$ One reason may be that it is difficult to selectively insert a guidewire through the SEMS opening into each stent lumen when the CBD is narrow.

One solution to this problem is to insert the guide wire into the stent lumen in a loop shape. If the guide wire is inserted into the SEMS lumen in a loop shape, it is easier to determine if the guide wire is inserted through the stent opening. However, with the loop shape, if the degree of stenosis is strong, the guide wire does not exceed the stenosis, so it is necessary to release the loop and search with the tip.

In SBS placement, unlike SIS placement, covered SEMSs can be used. There have been several previous studies assessing SBS placement using covered SEMSs. ${ }^{35,36}$ If the membrane of the covered SEMS is fully covered rather than partially covered, the SEMS can be removed during E-RI, thus solving the problem of guidewire manipulation through the stent mesh, which is a major problem in E-RI for MHBO. In fact, in a comparative study of SBS with a 6-mm fully covered SEMS and a partially fully covered SEMS for MHBO, the success rate of E-RI was $100 \%$ for the fully covered SEMS group and 75\% for the partially fully covered SEMS. ${ }^{36}$ The usefulness of SBS using a smalldiameter fully covered SEMS should be investigated in the future.

Recently, a study reported on SBS placement across the papilla using $6 \mathrm{~mm}$ fully covered SEMSs with E-RI from the time of initial drainage. ${ }^{37}$ They found that this shape allows easy guidewire guidance to the drainage area and easy replacement of the SEMS. However, this has yet to be evaluated using a multicenter approach.

\section{E-RI OF EUS-BD FOR MBO}

Several previous meta-analyses have reported that EUS$\mathrm{BD}$ has fewer stent dysfunctions than ERBD. ${ }^{38-41}$ One of the possible reasons could be that among EUS-BD-related procedures, the stent inserted by EUS-guided hepaticogastrostomy (EUS-HGS) or EUS-guided choledochoduodenostomy (EUS-CDS) does not traverse the tumor, which may reduce the risk of tumor in/overgrowth compared to a trans-papillary inserted ERBD stent. ${ }^{42}$

The E-RI of EUS-BD, as well as the E-RI of ERBD, is greatly influenced by whether the first indwelling stent is a SEMS or PS. The usefulness of EUS-BD-dedicated PS has also been previously reported. ${ }^{43-47}$ Recently, a two-step method has been established in which PS is first placed and then replaced with SEMS after fistula formation. If the initial indwelling PS is occluded, sufficient E-RI can be performed by replacing the PS.

On the other hand, if the first indwelling stent was is a SEMS, E-RI becomes challenging. In EUS-HGS, a SEMS longer than $100 \mathrm{~mm}$ is recommended to prevent stent migration. ${ }^{48-52}$ However, the long length of a SEMS in the gastric lumen makes it difficult to insert the device via the proximal end of the stent. Therefore, various E-RI methods have been reported for longer SEMSs in the gastric lumen (Table 2).

Importantly, an anti-migration technique for SEMS placed during ESU-HGS using hemoclips has been reported. In this technique, the hemoclips were endoscopically placed on the SEMS wall to form an acute angle to the gastric wall approximately 1 to $2 \mathrm{~cm}$ from the fistula. For stabilization, more than two wires of the stent were clipped simultaneously. Approximately three to four clips were used in one case, and they were placed in three different orientations: $0^{\circ}, 90^{\circ}$, and $180^{\circ} .^{53}$ In another report, in a case where the SEMS was about to migrate into the abdominal cavity due to dislocation, the covered mesh wall of the SEMS was broken by the ERCP cannula and two 5-F PS were inserted in a crisscross manner to prevent migration. $^{54}$

In the case of stent occlusion, E-RI is often challenging. If a fully covered SEMS is used, E-RI can be performed to place a new stent through the fistula after removal (Fig. 3). ${ }^{55}$ However, most SEMSs used for EUS-HGS are partially covered SEMSs that are not removable, and a new stent for E-RI must be placed in a SIS fashion. Nevertheless, 
Table 2. Review of Approaches to SEMS in the Gastric Lumen for Reintervention of Hepaticogastrostomy

\begin{tabular}{|c|c|c|c|c|}
\hline Author & $\begin{array}{l}\text { Reasons for } \\
\text { reintervention }\end{array}$ & $\begin{array}{c}\text { Use of electrosurgical } \\
\text { generators }\end{array}$ & Device to use & Summary of techniques \\
\hline Fujisawa et al. ${ }^{53}$ & Migration & No & Hemoclips & $\begin{array}{l}\text { Three or } 4 \text { hemoclips were endoscopically placed on the } \\
\text { SEMS wall to form an acute angle to the gastric wall } \\
\text { approximately } 1-2 \mathrm{~cm} \text { from the fistula. }\end{array}$ \\
\hline Shima et al. ${ }^{54}$ & Migration & No & Two 5-F PSs & $\begin{array}{l}\text { The covered mesh wall of the SEMS was broken by the } \\
\text { ERCP cannula and two 5-F PS were inserted with } \\
\text { crisscross manner to prevent migration. }\end{array}$ \\
\hline Yane et al. ${ }^{56}$ & Stent occlusion & Yes & Argon plasma coagulation & $\begin{array}{l}\text { After the covered mesh wall of the SEMS was broken by } \\
\text { argon plasma coagulation, new stent was inserted in } \\
\text { a SIS fashion. }\end{array}$ \\
\hline Ogura et al. ${ }^{57}$ & Stent occlusion & Yes & Diathermic dilator & $\begin{array}{l}\text { After the covered mesh wall of the SEMS was broken } \\
\text { by diathermic dilator, new stent was inserted in a SIS } \\
\text { fashion. }\end{array}$ \\
\hline Minaga et al..$^{58}$ & Stent occlusion & Yes & Precut needle knife & $\begin{array}{l}\text { After the covered mesh wall of the SEMS was broken by } \\
\text { precut needle knife, new stent was inserted in a SIS } \\
\text { fashion. }\end{array}$ \\
\hline Takenaka et al. ${ }^{59}$ & Stent occlusion & No & Balloon catheter for EPLBD & $\begin{array}{l}\text { The covered mesh wall of the SEMS was broken by the } \\
\text { tip of balloon catheter for EPLBD. After large balloon } \\
\text { dilation, new stent was inserted in a SIS fashion. }\end{array}$ \\
\hline Okamoto et al..$^{60}$ & Stent occlusion & No & ENBD tube (a loop cutter) & $\begin{array}{l}\text { The ENBD tube was inserted from the proximal opening } \\
\text { of the SEMS, and later the ENBD tube was cut to an } \\
\text { appropriate length in the gastric lumen using a loop } \\
\text { cutter. }\end{array}$ \\
\hline Takenaka et al. ${ }^{61}$ & Stent occlusion & No & Dedicated long PS & $\begin{array}{l}\text { After removing an initial indwelling PS, a dedicated PS } \\
\text { of an appropriate length calculated from the fluoro- } \\
\text { scopic image was created using an ENBD tube and } \\
\text { indwelled through the fistula. }\end{array}$ \\
\hline
\end{tabular}

SEMS, self-expandable metallic stent; PS, plastic stent; ERCP, endoscopic retrograde cholangiopancreatography; SIS, stent-in-stent; EPLBD, endoscopic papillary large balloon dilation; ENBD, endoscopic nasobiliary drain.

some ingenious reintervention methods allowing for E-RI through the stent mesh close to the gastric puncture site have been reported.

Alternatively, methods for breaking the stent mesh using electrosurgical generator such as argon plasma coagulation, ${ }^{56}$ a diathermic dilator, ${ }^{57}$ and a precut needle-knife ${ }^{58}$ have been reported.

Methods for breaking the stent mesh without using electrosurgical generators have also been reported, including using a balloon catheter for endoscopic papillary large balloon dilation with a small gap between the guidewire and the tip. ${ }^{59}$ This method is simple and quick for spreading the mesh.

Importantly, it may be possible to insert a guide wire into the SEMS lumen through the gastric lumen side opening, but the stent to be inserted thereafter must be of an appropriate length. For such a situation, a method has been reported in which the endoscopic nasobiliary drain (ENBD) tube is temporarily placed in a stent in a stent fashion and then excised with a loop cutter at an appropriate length in the stomach. ${ }^{60}$

However, cutting the stent with a loop cutter in the gastric lumen is difficult and time-consuming. On the other hand, it has been reported that the required length can be measured in advance from fluoroscopic images, and that a long PS can be made from ENBD tube material and used for E-RI. ${ }^{61}$ In this method, for example, if it is determined that the E-RI requires a length of $25 \mathrm{~cm}$, the tube is cut at $25 \mathrm{~cm}$ from the end of the ENBD tube to make a long PS, and the rest of the ENBD tube is used as a pusher. This method is useful because the length can be adjusted appropriately depending on the case, and it is useful not only for E-RI of EUS-BD but also for E-RI of ERBD.

In the future, it will be necessary to develop an EUS-BD dedicated device with the possibility of E-RI in mind, such as the lumen-apposing metal stent, which can be removed after fistula formation, can easily perform E-RI, and can be placed in one step. ${ }^{62-65}$

\section{CONCLUSION}

To plan an appropriate E-RI strategy for biliary stent occlusion for $\mathrm{MBO}$, the following must be considered on a case-by-case basis: (1) Is the drainage urgent? (2) What is the cause of the occlusion? (3) What was the original 

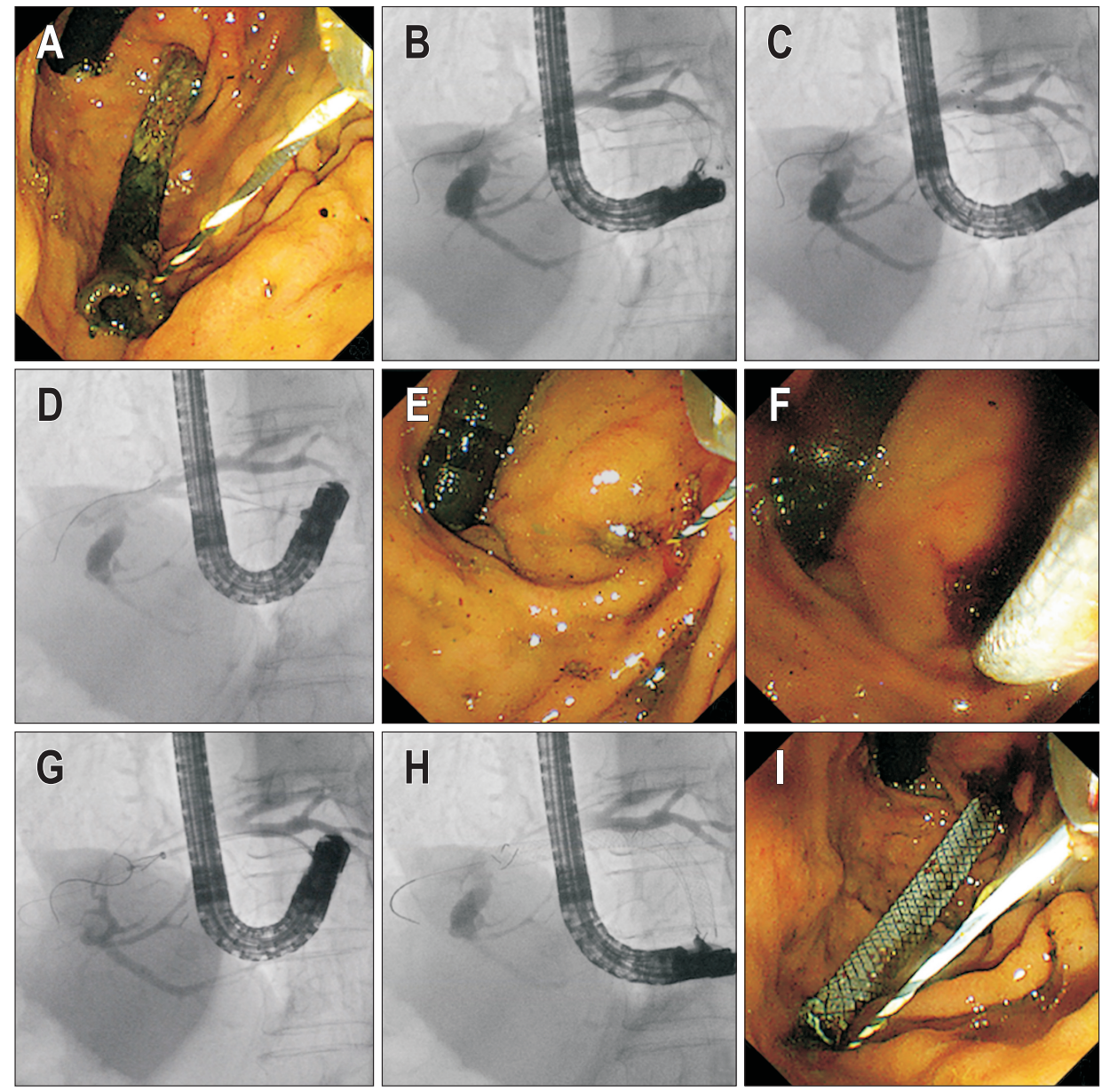

Fig. 3. Endoscopic reintervention for endoscopic ultrasound-guided hepaticogastrostomy. (A) In endoscopic reintervention for endoscopic ultrasound-guided hepaticogastrostomy, insertion of the device through the end of the stent in the gastric lumen is difficult. (B-D) The previously indwelled stent was a fully covered self-expandable metallic stent (SEMS), which could be grasped with grasping forceps and removed through the scope. (E) The guidewire inserted through the fistula into the bile duct could be seen. (F) A new SEMS delivery chip was inserted under this guidewire. (G-I) The new SEMS replacement was successful.

drainage route (PTBD/ERBD/EUS-BD)? (4) Was the initial stent a PS or SEMS? (5) In the case of SEMS, was it fully covered or uncovered?

Regardless of the original method of stent placement, if the inflammation from obstructive cholangitis is severe and/or the patient is exhibiting shock vitals, PTBD should be considered as the first choice.

In addition, we must keep in mind the possibility that the E-RI will be difficult. Last but not least, it is very important to establish a good relationship with the surgery or radiology department to have alternative treatments performed in cases of unsuccessful E-RI.

\section{CONFLICTS OF INTEREST}

No potential conflict of interest relevant to this article was reported.

\section{ORCID}

Mamoru Takenaka https://orcid.org/0000-0001-7308-4311 Masatoshi Kudo https://orcid.org/0000-0002-4102-3474

\section{REFERENCES}

1. Takenaka M, Fujita T, Sugiyama D, et al. What is the most adapted indication of prophylactic pancreatic duct stent within the high-risk group of post-endoscopic retrograde cholangiopancreatography pancreatitis? Using the propensity score analysis. J Hepatobiliary Pancreat Sci 2014;21:275280.

2. Takenaka M, Kudo M. Current status of endoscopic re-intervention for hilar malignant biliary obstruction. Dig Endosc 2021;33:746-748.

3. Logiudice FP, Bernardo WM, Galetti F, et al. Endoscopic 
ultrasound-guided vs endoscopic retrograde cholangiopancreatography biliary drainage for obstructed distal malignant biliary strictures: a systematic review and meta-analysis. World J Gastrointest Endosc 2019;11:281-291.

4. Conio M, Mangiavillano B, Caruso A, et al. Covered versus uncovered self-expandable metal stent for palliation of primary malignant extrahepatic biliary strictures: a randomized multicenter study. Gastrointest Endosc 2018;88:283-291.

5. Isayama H, Nakai Y, Kogure H, Yamamoto N, Koike K. Biliary self-expandable metallic stent for unresectable malignant distal biliary obstruction: which is better: covered or uncovered? Dig Endosc 2013;25 Suppl 2:71-74.

6. Kitano M, Yamashita Y, Tanaka K, et al. Covered selfexpandable metal stents with an anti-migration system improve patency duration without increased complications compared with uncovered stents for distal biliary obstruction caused by pancreatic carcinoma: a randomized multicenter trial. Am J Gastroenterol 2013;108:1713-1722.

7. Lee SJ, Kim MD, Lee MS, et al. Comparison of the efficacy of covered versus uncovered metallic stents in treating inoperable malignant common bile duct obstruction: a randomized trial. J Vasc Interv Radiol 2014;25:1912-1920.

8. Yang MJ, Kim JH, Yoo BM, et al. Partially covered versus uncovered self-expandable nitinol stents with anti-migration properties for the palliation of malignant distal biliary obstruction: a randomized controlled trial. Scand J Gastroenterol 2015;50:1490-1499.

9. Familiari P, Bulajic M, Mutignani M, et al. Endoscopic removal of malfunctioning biliary self-expandable metallic stents. Gastrointest Endosc 2005;62:903-910.

10. Shin HP, Kim MH, Jung SW, et al. Endoscopic removal of biliary self-expandable metallic stents: a prospective study. Endoscopy 2006;38:1250-1255.

11. Kida M, Miyazawa S, Iwai T, et al. Endoscopic management of malignant biliary obstruction by means of covered metallic stents: primary stent placement vs. re-intervention. Endoscopy 2011;43:1039-1044.

12. Cho JH, Jeon TJ, Park JY, et al. Comparison of outcomes among secondary covered metallic, uncovered metallic, and plastic biliary stents in treating occluded primary metallic stents in malignant distal biliary obstruction. Surg Endosc 2011;25:475-482.

13. Nennstiel S, Tschurtschenthaler I, Neu B, et al. Management of occluded self-expanding biliary metal stents in malignant biliary disease. Hepatobiliary Pancreat Dis Int 2018;17:4954.

14. Togawa $\mathrm{O}$, Kawabe $\mathrm{T}$, Isayama $\mathrm{H}$, et al. Management of occluded uncovered metallic stents in patients with malignant distal biliary obstructions using covered metallic stents. J Clin Gastroenterol 2008;42:546-549.

15. Ridtitid W, Rerknimitr R, Janchai A, Kongkam P, Treepraser- tsuk S, Kullavanijaya P. Outcome of second interventions for occluded metallic stents in patients with malignant biliary obstruction. Surg Endosc 2010;24:2216-2220.

16. Shah T, Desai S, Haque M, Dakik H, Fisher D. Management of occluded metal stents in malignant biliary obstruction: similar outcomes with second metal stents compared to plastic stents. Dig Dis Sci 2012;57:2765-2773.

17. Togawa $\mathrm{O}$, Isayama $\mathrm{H}$, Tsujino $\mathrm{T}$, et al. Management of dysfunctional covered self-expandable metallic stents in patients with malignant distal biliary obstruction. J Gastroenterol 2013;48:1300-1307.

18. Isayama $\mathrm{H}$, Mukai $\mathrm{T}$, Itoi $\mathrm{T}$, et al. Comparison of partially covered nitinol stents with partially covered stainless stents as a historical control in a multicenter study of distal malignant biliary obstruction: the WATCH study. Gastrointest Endosc 2012;76:84-92.

19. Kogure H, Ryozawa S, Maetani I, et al. A prospective multicenter study of a fully covered metal stent in patients with distal malignant biliary obstruction: WATCH-2 Study. Dig Dis Sci 2018;63:2466-2473.

20. Bismuth H, Castaing D, Traynor O. Resection or palliation: priority of surgery in the treatment of hilar cancer. World J Surg 1988;12:39-47.

21. Bismuth H, Nakache R, Diamond T. Management strategies in resection for hilar cholangiocarcinoma. Ann Surg 1992;215:31-38.

22. Kongkam P, Orprayoon T, Boonmee C, et al. ERCP plus endoscopic ultrasound-guided biliary drainage versus percutaneous transhepatic biliary drainage for malignant hilar biliary obstruction: a multicenter observational open-label study. Endoscopy 2021;53:55-62.

23. Takahashi E, Fukasawa M, Sato T, et al. Biliary drainage strategy of unresectable malignant hilar strictures by computed tomography volumetry. World J Gastroenterol 2015;21:4946-4953.

24. Vienne A, Hobeika E, Gouya H, et al. Prediction of drainage effectiveness during endoscopic stenting of malignant hilar strictures: the role of liver volume assessment. Gastrointest Endosc 2010;72:728-735.

25. Inatomi O, Bamba S, Shioya M, et al. Threaded biliary inside stents are a safe and effective therapeutic option in cases of malignant hilar obstruction. BMC Gastroenterol 2013;13:31.

26. Itoi T, Sofuni A, Itokawa F, Tonozuka R, Ishii K. Current status and issues regarding biliary stenting in unresectable biliary obstruction. Dig Endosc 2013;25 Suppl 2:63-70.

27. Lee TH, Moon JH, Choi HJ, et al. Third metal stent for revision of malignant hilar biliary strictures. Endoscopy 2016;48:1129-1133.

28. Lee TH, Moon JH, Kim JH, et al. Primary and revision efficacy of cross-wired metallic stents for endoscopic bilateral stent-in-stent placement in malignant hilar biliary strictures. 
Endoscopy 2013;45:106-113.

29. Kogure $H$, Isayama $H$, Nakai $Y$, et al. High single-session success rate of endoscopic bilateral stent-in-stent placement with modified large cell Niti-S stents for malignant hilar biliary obstruction. Dig Endosc 2014;26:93-99.

30. Lee JM, Lee SH, Chung KH, et al. Small cell- versus large cell-sized metal stent in endoscopic bilateral stent-in-stent placement for malignant hilar biliary obstruction. Dig Endosc 2015;27:692-699.

31. Ogura T, Takenaka M, Shiomi H, et al. Single-session multiple stent deployment using moving cell stent without dilating initial stent mesh to treat malignant hilar biliary obstruction (with videos). J Hepatobiliary Pancreat Sci 2020;27:8489.

32. Takenaka M, Yamao K, Minaga K, et al. Novel metallic stent designed for endoscopic bilateral stent-in-stent placement in patients with hilar malignant biliary obstruction. Endoscopy 2019;51:E30-E31.

33. Takenaka M, Nakai A, Kudo M. Novel concept of bared type metallic stent for endoscopic bilateral stent-in-stent placement in patients with hilar malignant biliary obstruction (with video). J Hepatobiliary Pancreat Sci 2020;27:282-283.

34. Inoue T, Naitoh I, Suzuki Y, et al. Multi-center study of endoscopic revision after side-by-side metal stent placement for malignant hilar biliary obstruction. Dig Endosc 2021;33:807814.

35. Inoue T, Okumura F, Naitoh I, et al. Feasibility of the placement of a novel 6-mm diameter threaded fully covered selfexpandable metal stent for malignant hilar biliary obstructions (with videos). Gastrointest Endosc 2016;84:352-357.

36. Yoshida T, Hara K, Imaoka H, et al. Benefits of side-by-side deployment of 6-mm covered self-expandable metal stents for hilar malignant biliary obstructions. J Hepatobiliary Pancreat Sci 2022;54:E102-E105.

37. Takenaka M, Yamazaki T, Otsuka Y, Takashima K, Ishikawa R, Kudo M. Across-the-papilla side-by-side placement of 6-mm fully covered metallic stents for malignant hilar biliary obstruction: a novel concept that may facilitate reintervention. Endoscopy 2022;54:E102-E105.

38. Han SY, Kim SO, So H, Shin E, Kim DU, Park DH. EUSguided biliary drainage versus ERCP for first-line palliation of malignant distal biliary obstruction: a systematic review and meta-analysis. Sci Rep 2019;9:16551.

39. Li DF, Zhou CH, Wang LS, Yao J, Zou DW. Is ERCP-BD or EUS-BD the preferred decompression modality for malignant distal biliary obstruction? A meta-analysis of randomized controlled trials. Rev Esp Enferm Dig 2019;111:953960.

40. Lyu Y, Li T, Cheng Y, Wang B, Cao Y, Wang Y. Endoscopic ultrasound-guided vs ERCP-guided biliary drainage for malignant biliary obstruction: a up-to-date meta-analysis and systematic review. Dig Liver Dis 2021;53:1247-1253.

41. Miller CS, Barkun AN, Martel M, Chen YI. Endoscopic ultrasound-guided biliary drainage for distal malignant obstruction: a systematic review and meta-analysis of randomized trials. Endosc Int Open 2019;7:E1563-E1573.

42. Dhir V, Itoi T, Khashab MA, et al. Multicenter comparative evaluation of endoscopic placement of expandable metal stents for malignant distal common bile duct obstruction by ERCP or EUS-guided approach. Gastrointest Endosc 2015;81:913-923.

43. Umeda J, Itoi $T$, Tsuchiya $T$, et al. A newly designed plastic stent for EUS-guided hepaticogastrostomy: a prospective preliminary feasibility study (with videos). Gastrointest Endosc 2015;82:390-396.

44. Ogura T, Nishioka N, Higuchi K. EUS-guided hepaticojejunostomy using novel plastic stent combined with antegrade metal stent placement. J Gastrointest Surg 2018;22:13091311.

45. Yamamoto K, Itoi T, Tsuchiya T, et al. EUS-guided antegrade metal stenting with hepaticoenterostomy using a dedicated plastic stent with a review of the literature (with video). Endosc Ultrasound 2018;7:404-412.

46. Shiomi H, Masuda A, Kodama Y. Novel approach for successful endoscopic ultrasound-guided hepaticogastrostomy using a double-guidewire technique. Dig Endosc 2019;31:e50-e51.

47. Mukai S, Itoi T, Sofuni A, et al. Urgent and early EUS-guided biliary drainage in patients with acute cholangitis. Endosc Ultrasound 2021;10:191-199.

48. Kamata K, Takenaka M, Minaga K, et al. Stent migration during EUS-guided hepaticogastrostomy in a patient with massive ascites: troubleshooting using additional EUS-guided antegrade stenting. Arab J Gastroenterol 2017;18:120-121.

49. Minaga K, Kitano M. Recent advances in endoscopic ultrasound-guided biliary drainage. Dig Endosc 2018;30:38-47.

50. Minaga K, Kitano M, Yamashita Y, Nakatani Y, Kudo M. Stent migration into the abdominal cavity after EUS-guided hepaticogastrostomy. Gastrointest Endosc 2017;85:263-264.

51. Nakai Y, Isayama H, Yamamoto N, et al. Safety and effectiveness of a long, partially covered metal stent for endoscopic ultrasound-guided hepaticogastrostomy in patients with malignant biliary obstruction. Endoscopy 2016;48:1125-1128.

52. Okuno N, Hara K, Mizuno N, Hijioka S, Imaoka H, Yamao $\mathrm{K}$. Stent migration into the peritoneal cavity following endoscopic ultrasound-guided hepaticogastrostomy. Endoscopy 2015;47 Suppl 1 UCTN:E311.

53. Fujisawa T, Isayama H, Ishii S. "ClipFlap" anchoring method for endoscopic ultrasonography-guided hepaticogastrostomy with a covered self-expandable metallic stent. Dig Endosc 2020;32:628.

54. Shima Y, Isayama H, Ito Y, et al. Crisscross anchor-stents 
to prevent metal stent migration during endoscopic ultrasound-guided hepaticogastrostomy. Endoscopy 2014;46 Suppl 1 UCTN:E563.

55. Kawakubo K, Isayama H, Kogure H, et al. Exchange of selfexpandable metal stent in endoscopic ultrasound-guided hepaticogastrostomy. Endoscopy 2012;44 Suppl 2 UCTN:E311E312.

56. Yane K, Katanuma A, Maguchi H, et al. Successful reintervention with metal stent trimming using argon plasma coagulation after endoscopic ultrasound-guided hepaticogastrostomy. Endoscopy 2014;46 Suppl 1 UCTN:E391-E392.

57. Ogura T, Masuda D, Takeuchi T, Fukunishi S, Higuchi K. Simplified reintervention method of EUS-guided hepaticogastrostomy stent obstruction. Gastrointest Endosc 2016;83:831.

58. Minaga K, Takenaka M, Okamoto A, et al. Reintervention for stent occlusion after endoscopic ultrasound-guided hepaticogastrostomy with novel use of a precut needle-knife. Endoscopy 2018;50:E153-E154.

59. Takenaka M, Nakai A, Kudo M. Large balloon expansion method for re-intervention after endoscopic ultrasoundguided hepaticogastrostomy for stent obstruction. Dig Endosc 2019;31:e99-e100.

60. Okamoto A, Minaga K, Takenaka M, et al. A novel technique for stent dysfunction after endoscopic ultrasound-guided hepaticogastrostomy with antegrade stenting. Endoscopy 2019;51:E255-E256.

61. Takenaka M, Minaga K, Yoshikawa T, et al. Novel concept using a plastic stent for endoscopic ultrasound-guided hepaticogastrostomy adjusting the length according to the patient's anatomy. Endoscopy 2019;51:E362-E363.

62. Anderloni A, Troncone E, Fugazza A, et al. Lumen-apposing metal stents for malignant biliary obstruction: Is this the ultimate horizon of our experience? World J Gastroenterol 2019;25:3857-3869.

63. Chin JY, Seleq S, Weilert F. Safety and outcomes of endoscopic ultrasound-guided drainage for malignant biliary obstruction using cautery-enabled lumen-apposing metal stent. Endosc Int Open 2020;8:E1633-E1638.

64. de Benito Sanz M, Nájera-Muñoz R, de la Serna-Higuera $\mathrm{C}$, et al. Lumen apposing metal stents versus tubular selfexpandable metal stents for endoscopic ultrasound-guided choledochoduodenostomy in malignant biliary obstruction. Surg Endosc 2021;35:6754-6762.

65. Tarantino I, Peralta M, Ligresti D, et al. Endoscopic ultrasound-guided biliary drainage of malignant stenosis, not treatable with endoscopic retrograde cholangiopancreatography: a single-center, prospective observational study. Endosc Int Open 2021;9:E110-E115. 